\title{
PENYELESAIAN PERSAMAAN ADVEKSI NONLOKAL DALAM KASUS DOMAIN SATU DIMENSI DENGAN MENGGUNAKAN METODE KARAKTERISTIK
}

\author{
INDAH CITRA APSARI, MAHDHIVAN SYAFWAN, AHMAD IQBAL BAQI \\ Jurusan Matematika, \\ Fakultas Matematika dan Ilmu Pengetahuan Alam, Universitas Andalas, \\ Kampus UNAND Limau Manis Padang, Indonesia. \\ email : indahcitraapsari70@gmail.com
}

\begin{abstract}
Abstrak. Makalah ini membahas penyelesaian persamaan adveksi nonlokal dalam domain satu dimensi pada kasus nonlinier. Untuk mencari solusi dari persamaan adveksi nonlokal, digunakan metode karakteristik dengan syarat awal yang diberikan dan syarat batas nol. Kasus penerapan yang dibahas dari persamaan adveksi ini adalah proses pencernaan makanan di dalam usus organisme. Solusi dari persamaan adveksi nonlokal yang diperoleh pada kasus ini menunjukkan bahwa konsentrasi nutrisi makanan dalam usus meningkat secara linier dengan kecepatan perambatan semakin lama semakin berkurang. Hal ini konsisten dengan kenyataan bahwa makanan yang merambat di dalam usus dengan kecepatan yang bergantung pada kualitas (konsentrasi nutrisi) makanan.
\end{abstract}

Kata Kunci: Persamaan adveksi nonlokal, metode karakteristik, pencernaan makanan

\section{Pendahuluan}

Persamaan adveksi adalah salah satu persamaan diferensial parsial yang memodelkan pergerakan suatu konsentrat dalam cairan yang mengalir, dengan asumsi konsentrat tersebut tidak mengalami proses difusi di dalam cairan [2]. Persamaan adveksi juga dikenal sebagai persamaan transport atau persamaan konveksi. Salah satu masalah yang sering diabaikan dalam kajian persamaan adveksi adalah fenomena nonlokal.

Persamaan adveksi nonlokal banyak ditemui dalam berbagai aplikasi. Salah satu diantaranya adalah pada proses pencernaan makanan dalam usus organisme. Selama ini diyakini bahwa makanan merambat di dalam usus dengan kecepatan yang bergantung pada kualitas (konsentrasi nutrisi) makanan; makanan berkualitas rendah merambat dengan cepat, sedangkan makanan berkualitas tinggi merambat secara perlahan untuk mendapatkan penyerapan nutrisi secara maksimal di dalam usus [3].

Dalam penelitian ini, persamaan adveksi nonlokal akan dianalisis dengan menggunakan metode karakteristik. Kajian pada penelitian ini mengeksplorasi kembali studi pada referensi [3] yang membahas penyelesaian persamaan adveksi nonlokal dalam domain satu dimensi. Kurva karakteristik dari persamaan adveksi nonlokal digambarkan dengan menggunakan aplikasi software MATLAB R2013a. 


\section{Persamaan Adveksi Nonlokal}

Misalkan $u=u(x, t)$ menyatakan kerapatan atau konsentrasi dari suatu kuantitas (organisme, partikel, energi dan lain-lain) dalam domain satu dimensi $0<x<1$, dan misalkan $\phi=\phi(x, t)$ menyatakan fluks dari kuantitas tersebut, maka hukum konservasi dasar (tanpa fungsi sumber) diberikan oleh [2] :

$$
u_{t}+\phi_{x}=0 .
$$

Asumsikan bahwa fluks sebanding dengan konsentrasi, yaitu $\phi=c u$ dimana $c$ menyatakan kecepatan. Dengan demikian $\phi_{x}=c u_{x}$, sehingga diperoleh persamaan adveksi linier homogen:

$$
u_{t}+c u_{x}=0,
$$

yang memiliki solusi gelombang berjalan $u=f(x-c t)$. Jika fluks dinyatakan sebagai $\phi=\phi(u)$, maka $\phi_{x}=\phi^{\prime}(u) u_{x}$, sehingga diperoleh persamaan adveksi nonlinier homogen

$$
u_{t}+c(u) u_{x}=0, \quad c(u)=\phi^{\prime}(u),
$$

dimana $c(u)$ menyatakan kecepatan yang bergantung pada $u$ (solusinya sendiri). Persamaan (2.2) dan (2.3) dapat diselesaikan dengan menggunakan metode karakteristik, sebagaimana yang telah dijelaskan pada [2].

Dalam hal yang berbeda, kecepatan juga dapat dinyatakan sebagai integral dari suatu fungsi terhadap $u$, yaitu fluks diberikan dalam bentuk [3]

$$
\phi=v(t) u=\left(\int_{a}^{b} F(u(x, t)) d x\right) u, \quad a \leq x \leq b,
$$

dimana $F$ adalah suatu fungsi yang diberikan. Kasus ini dikenal sebagai masalah nonlokal. Dengan mensubstitusikan persamaan (2.4) ke persamaan (2.1), maka diperoleh persamaan adveksi nonlokal nonlinier berikut:

$$
u_{t}+\left(\int_{0}^{1} F(u(x, t)) d x\right) u_{x}=0 .
$$

Contoh masalah nonlokal dapat ditemukan pada proses pencernaan makanan di dalam usus organisme, dimana kecepatan perambatan makanan di dalam usus bergantung pada massa total makanan. Selama ini diyakini bahwa makanan merambat di dalam usus dengan kecepatan yang bergantung pada kualitas (konsentrasi nutrisi) makanan; makanan berkualitas rendah merambat dengan cepat, sedangkan makanan berkualitas tinggi merambat secara perlahan untuk mendapatkan penyerapan nutrisi secara maksimal di dalam usus.

\section{Konstruksi Solusi}

Pandang kembali persamaan adveksi nonlokal yang diberikan oleh

$$
u_{t}+\left(\int_{0}^{1} F(u(x, t)) d x\right) u_{x}=0, \quad 0 \leq x \leq 1, \quad t \geq 0,
$$


dengan syarat awal

$$
u(x, 0)=f(x), \quad 0 \leq x \leq 1,
$$

dan syarat batas

$$
u(0, t)=0, \quad t \geq 0
$$

Asumsikan bahwa konsentrasi awal $f$ dan fungsi $F$ merupakan fungsi mulus (terdiferensialkan dan kontinu) nonnegatif. Persamaan (3.1) dapat ditulis ulang dalam bentuk

$$
u_{t}+v(t) u_{x}=0
$$

dimana

$$
v(t)=\int_{0}^{1} F(u(x, t)) d x
$$

menyatakan kecepatan aliran yang nilainya tidak diketahui.

Masalah adveksi nonlokal ini akan diselesaikan dengan menggunakan metode karakteristik. Sebagaimana yang dijelaskan pada [2], kurva karakteristik adalah kurva $(x(t), t)$ yang menelusuri posisi $u(x, t)$ yang bernilai konstan. Hal ini berarti $\frac{d u}{d t}=0$. Lebih lanjut, dengan menggunakan aturan rantai diperoleh

$$
\frac{d u}{d t}=\frac{\partial u}{\partial t} \frac{d t}{d t}+\frac{\partial u}{\partial x} \frac{d x}{d t}=u_{t}+\frac{d x}{d t} u_{x}=0 .
$$

Dengan melihat hubungan antara persamaan (3.4) dan (3.6), maka diperoleh

$$
\frac{d x}{d t}=v(t)
$$

Dengan demikian, kurva karakteristik $(x(t), t)$ dapat ditentukan dengan menyelesaikan persamaan diferensial (3.7).

Dengan integrasi sederhana, persamaan (3.7) menjadi

$$
x=\varphi(t) \equiv \int_{0}^{t} v(s) d s,
$$

yang merupakan persamaan karakteristik utama [berasal dari titik awal $(0,0)$ ] atau disebut sinyal utama. Karena nilai $u$ konstan di sepanjang kurva karakteristik utama, maka nilai $u$ di masing-masing titik pada kurva tersebut sama dengan nilai $u$ di titik awal $(0,0)$. Dengan menggunakan syarat awal (3.2), solusi persamaan adveksi nonlokal (3.1) pada sinyal utama diberikan oleh

$$
u(x, t)=u(0,0)=f(0), \quad \text { untuk } \quad x=\varphi(t) .
$$

Analisis selanjutnya adalah menentukan kurva karakteristik di belakang sinyal utama $(0 \leq x<\varphi(t))$ dan di depan sinyal utama $(\varphi(t)<x \leq 1)$ [lihat Gambar 1]. 


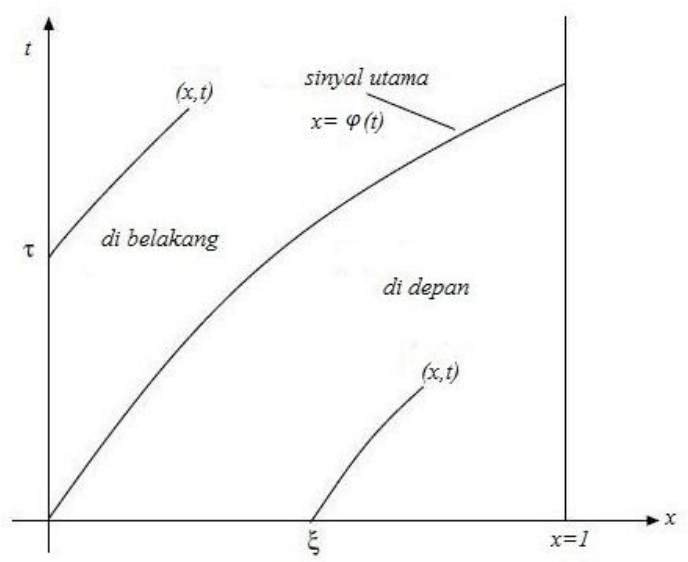

Gambar 1. Diagram kurva karakteristik dari persamaan adveksi nonlokal dengan syarat batas nol.

\subsection{Kurva Karakteristik di Belakang Sinyal Utama}

Di belakang sinyal utama, yaitu pada $0 \leq x<\varphi(t)$, kurva karakteristik yang berasal dari $(0, \tau)$ ke $(x, t)$ dapat ditulis

$$
x=\int_{\tau}^{t} v(s) d s=\varphi(t)-\varphi(\tau) .
$$

Karena $u$ konstan di sepanjang kurva karakteristik, yang mengakibatkan nilai $u$ di masing-masing titik pada kurva sama dengan nilai $u$ di titik awal $(0, \tau)$, dan dengan menggunakan syarat batas (3.3), maka solusi persamaan adveksi nonlokal (3.1) di belakang sinyal utama adalah

$$
u(x, t)=u(0, \tau)=0, \quad \text { untuk } \quad 0 \leq x<\varphi(t) .
$$

\subsection{Kurva Karakteristik di Depan Sinyal Utama}

Di depan sinyal utama, yaitu pada $\varphi(t)<x \leq 1$, kurva karakteristik yang berasal dari $(\xi, 0)$ ke $(x, t)$ dapat ditulis dengan $x=\varphi(t)+\xi$. Karena $u$ bernilai konstan pada kurva karakteristik yang menghubungkan $(\xi, 0)$ ke $(x, t)$, maka dengan menggunakan syarat awal (3.2) diperoleh $u(x, t)=u(\xi, 0)=f(\xi)$. Dengan demikian solusi persamaan adveksi nonlokal (3.1) di depan sinyal utama adalah

$$
u(x, t)=f(\xi)=f(x-\varphi(t)), \quad \text { untuk } \quad \varphi(t)<x \leq 1 .
$$

Perhatikan bahwa $\varphi(t)$ perlu ditentukan. Untuk melakukan itu, tulis persamaaan (3.5) pada $\varphi(t)<x \leq 1$ sebagai

$$
v(t)=\int_{\varphi(t)}^{1} F(u(x, t)) d x .
$$


Dengan menggunakan Aturan Integral Leibniz [4] dan dari persamaan (3.1) diperoleh

$$
\begin{aligned}
v^{\prime}(t) & =\int_{\varphi(t)}^{1} F^{\prime}(u) u_{t}(x, t) d x-F(u(\varphi(t), t)) \varphi^{\prime}(t) \\
& =-v(t) \int_{\varphi(t)}^{1} F^{\prime}(u) u_{x} d x-F(u(\varphi(t), t)) \varphi^{\prime}(t) \\
& =-v(t) \int_{\varphi(t)}^{1} \frac{\partial}{\partial x} F(u) d x-F(u(\varphi(t), t)) \varphi^{\prime}(t) \\
& =-v(t) F(u(1, t))+v(t) F(u(\varphi(t), t))-\varphi^{\prime}(t) F(u(\varphi(t), t)) .
\end{aligned}
$$

Dengan menerapkan aturan dasar kalkulus pada persamaan (3.8), diperoleh hubungan $v(t)=\varphi^{\prime}(t)$. Selanjutnya dari persamaan (3.12) diperoleh $u(1, t)=f(1-\varphi(t))$. Dengan demikian persamaan (3.14) menjadi

$$
v^{\prime}(t)=\varphi^{\prime \prime}(t)=-\varphi^{\prime}(t)(F \circ f)(1-\varphi(t)) .
$$

Dari persamaan (3.8) diperoleh $\varphi(0)=0$. Dengan menggunakan syarat batas $(3.3)$, maka pada saat $t=0$, persamaan (3.13) menjadi

$$
v(0)=\int_{0}^{1}(F \circ f)(x) d x .
$$

Perhatikan bahwa persamaan (3.15) merupakan persamaan diferensial orde dua untuk $\varphi$. Misalkan $w=\varphi^{\prime}$, maka

$$
\varphi^{\prime \prime}=w^{\prime}=\frac{d w}{d \varphi} \frac{d \varphi}{d t}=\frac{d w}{d \varphi} w=w \frac{d w}{d \varphi} .
$$

Karena $w=\varphi^{\prime}$, maka berdasarkan persamaan (3.17), persamaan (3.15) menjadi

$$
\frac{d w}{d \varphi}=-(F \circ f)(1-\varphi)
$$

Integrasi persamaan (3.18) dari 0 ke $\varphi(t)$ diberikan sebagai berikut:

$$
w(\varphi)=w(0)-\int_{0}^{\varphi}(F \circ f)(1-r) d r,
$$

dimana $w(0)=\varphi^{\prime}(0)=v(0)$ diberikan oleh persamaan (3.16). Persamaan (3.19) mendefinisikan $w$ sebagai fungsi terhadap $\varphi$. Sekarang $\varphi(t)$ dapat ditentukan dari $\varphi^{\prime}=w$ dengan syarat awal $\varphi(0)=0$.

\section{Aplikasi pada Proses Pencernaan Makanan dalam Usus}

Dalam subbab ini, akan dijelaskan aplikasi persamaan adveksi nonlokal pada proses pencernaan makanan dalam usus dengan interval [0,1]. Dalam hal ini, konsentrasi awal nutrisi makanan dalam usus diberikan oleh $f(x)=x$, artinya konsentrasi nutrisi makanan di dalam usus semakin ke ujung semakin meningkat secara linier. Selanjutnya diberikan $F(u)=u$, artinya $\int_{0}^{1} F(u) d x=\int_{0}^{1} u d x$ menyatakan massa total dari nutrisi makanan dalam usus dengan interval $[0,1]$. 
Persamaan adveksi nonlokal untuk kasus ini diberikan oleh

$$
u_{t}+\left(\int_{0}^{1} u d x\right) u_{x}=0, \quad 0 \leq x \leq 1, \quad t \geq 0
$$

dengan syarat awal

$$
u(x, 0)=x, \quad 0 \leq x \leq 1
$$

dan syarat batas

$$
u(0, t)=0, \quad t \geq 0 .
$$

Karena $F(f(x))=f(x)=x$, maka persamaan (3.16) menjadi

$$
v(0)=\frac{1}{2}
$$

Perhatikan bahwa $(F \circ f)(1-r)=F(f(1-r))=f(1-r)=1-r$ dan $w(0)=v(0)$. Dengan demikian persamaan (3.19) menjadi

$$
\begin{aligned}
w(\varphi) & =w(0)-\int_{0}^{\varphi}(F \circ f)(1-r) d r \\
& =\frac{1}{2} \varphi^{2}-\varphi+\frac{1}{2}
\end{aligned}
$$

Karena $w=\frac{d \varphi}{d t}$, maka

$$
\begin{aligned}
\int \frac{1}{\frac{1}{2} \varphi^{2}-\varphi+\frac{1}{2}} d \varphi & =\int 1 d t \\
\frac{-2}{\varphi-1} & =t+C,
\end{aligned}
$$

dimana $C$ adalah suatu konstanta integrasi. Dari syarat awal $\varphi(0)=0$, diperoleh $C=2$, sehingga persamaan terakhir menjadi

$$
\varphi(t)=\frac{t}{t+2} .
$$

Berdasarkan hasil analisis pada subbab sebelumnya, diperoleh solusi pada sinyal utama [persamaan (3.9)] sebagai berikut:

$$
u(x, t)=f(0)=0, \quad \text { untuk } \quad x=\frac{t}{t+2} .
$$

Selanjutnya dengan menggunakan aturan dasar kalkulus pada persamaan (3.8), diperoleh hubungan

$$
\frac{d}{d t} \varphi(t)=v(t)
$$

Oleh karena itu kecepatan aliran, yaitu $v(t)$ pada persamaan (3.1), adalah

$$
v(t)=\frac{2}{(t+2)^{2}} .
$$

Dengan demikian, solusi di depan sinyal utama [persamaan (3.12)] adalah

$$
u(x, t)=x-\frac{t}{t+2}, \quad \text { untuk } \quad \frac{t}{t+2}<x \leq 1,
$$


sedangkan solusi di belakang sinyal utama [persamaan (3.11)] adalah

$$
u(x, t)=0, \quad \text { untuk } \quad 0 \leq x<\frac{t}{t+2} .
$$

Kurva karakteristik dari persamaan (4.1) ditampilkan pada Gambar 2.

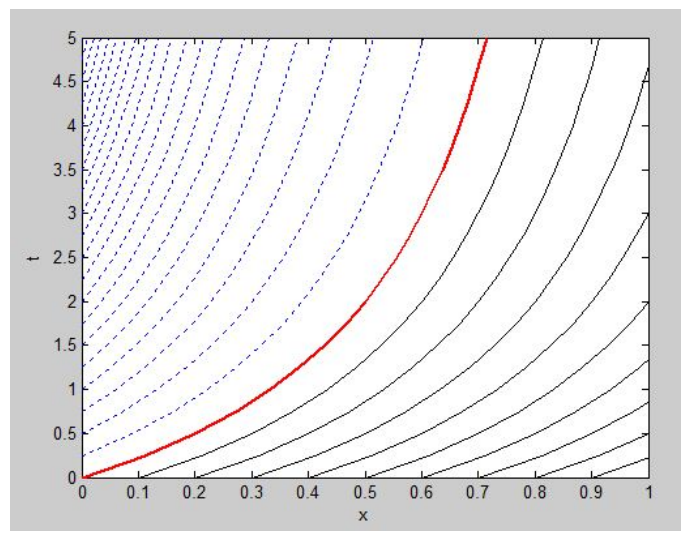

Gambar 2. Kurva karakteristik dari persamaan (4.1)

Plot solusi dalam bidang- $x u$ pada saat $t=0 ; 0,25 ; 0,5 ; 0,75 ; 1$ diberikan pada Gambar 3 .

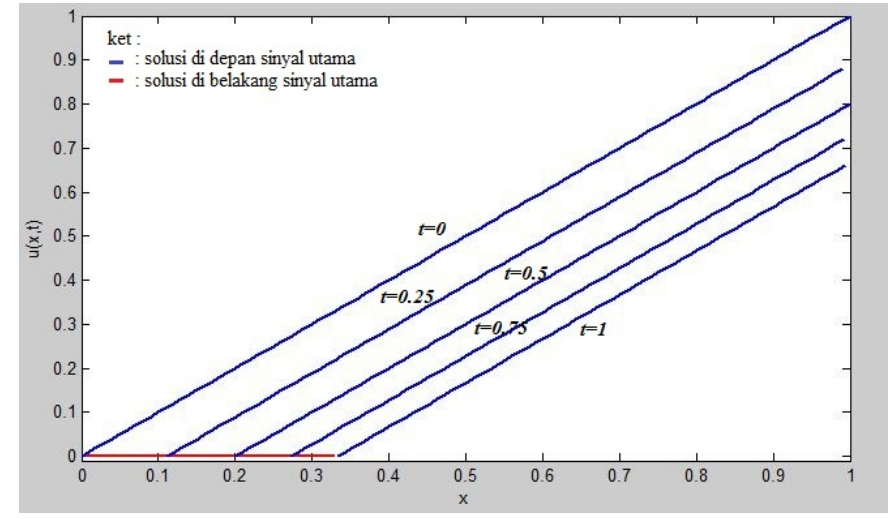

Gambar 3. Solusi di depan sinyal utama (biru) dan di belakang sinyal utama (merah) pada saat $t=0 ; 0,25 ; 0,5 ; 0,75 ; 1$.

Selanjutnya, untuk memberikan gambaran lebih jelas dari solusi $u(x, t)$ pada Gambar 4 diperlihatkan plot solusi dalam ruang tiga dimensi.

Dari Gambar 3 dan 4 dapat disimpulkan bahwa konsentrasi nutrisi makanan dalam usus semakin meningkat secara linier dan kecepatan perambatan makanan dalam usus semakin lama semakin berkurang. Hal ini konsisten dengan kenyataan 


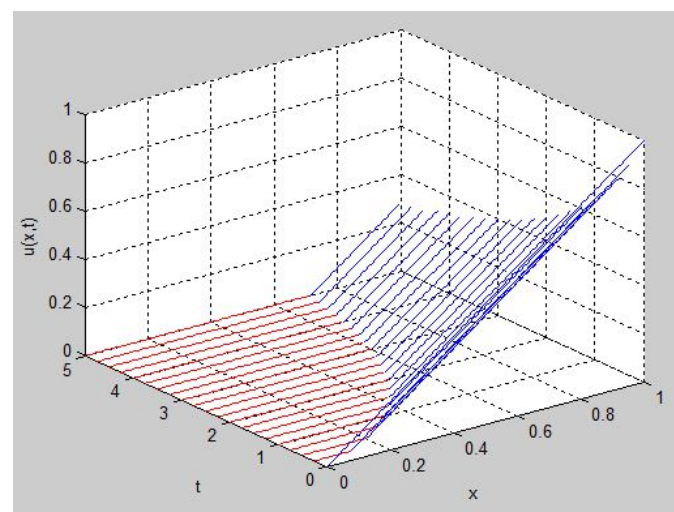

Gambar 4. Solusi $u(x, t)$ dalam ruang tiga dimensi.

bahwa makanan merambat di dalam usus dengan kecepatan yang bergantung pada kualitas (konsentrasi nutrisi) makanan; makanan berkualitas rendah merambat dengan cepat, sedangkan makanan berkualitas tinggi merambat secara perlahan untuk mendapatkan penyerapan nutrisi secara maksimal di dalam usus.

\section{Kesimpulan}

Pada penelitian ini telah dibahas mengenai penyelesaian persamaan adveksi nonlokal dengan menggunakan metode karakteristik. Kasus yang ditinjau untuk menyelesaikan persamaan adveksi nonlokal ini yaitu kasus dengan syarat batas nol. Persamaan adveksi nonlokal untuk kasus ini diberikan oleh

$$
u_{t}+\left(\int_{0}^{1} F(u(x, t)) d x\right) u_{x}=0, \quad 0 \leq x \leq 1, \quad t \geq 0,
$$

dengan syarat awal $u(x, 0)=f(x), 0 \leq x \leq 1$ dan syarat batas $u(0, t)=0, t \geq 0$.

Dari hasil analisis terhadap kurva karakteristik, diperoleh tiga solusi untuk kasus ini, yaitu :

1. Solusi pada sinyal utama adalah $u(x, t)=f(0)$, untuk $x=\varphi(t)$,

2. Solusi di depan sinyal utama adalah $u(x, t)=f(\xi)=f(x-\varphi(t))$, untuk $\varphi(t)<$ $x \leq 1$,

3. Solusi di belakang sinyal utama adalah $u(x, t)=0$, untuk $0 \leq x<\varphi(t)$,

dimana $\varphi(t)$ diperoleh dengan menyelesaikan persamaan diferensial

$$
w=\frac{d \varphi}{d t},
$$

dengan $w(\varphi)=w(0)-\int_{0}^{\varphi}(F \circ f)(1-r) d r$ dan syarat awal $\varphi(0)=0$.

\section{Ucapan Terima kasih}

Terima kasih kepada bapak Dr. Mahdhivan Syafwan dan bapak Dr. Ahmad Iqbal Baqi selaku pembimbing saya dalam mengerjakan penelitian ini. Juga kepada Ibu 
84 Indah Citra Apsari dkk

Dr. Susila Bahri, Ibu Monika Rianti Helmi, M.Si dan Ibu Riri Lestari, M.Si selaku penguji sehingga penelitian ini dapat terlaksana dengan baik.

\section{Daftar Pustaka}

[1] Boyce, William E dan Richard C. Diprima. 2009.Elementary Differential Equations and Boundary Value Problems. John Wiley and Sons: New York.

[2] Knobel, Roger. 2000. An Introduction to the Mathematical Theory of Waves. 3th. American Mathematical Society: New York.

[3] Logan, J. David. 2003. Nonlocal Advection Equations. International Journal of Mathematical Education in Science and Technology 34, 271-277.

[4] Ramana, B.V. 2007. Higher Engineering Mathematics. Tata McGraw - Hill Publishing : New Delhi. 